ORIGINAL ARTICLE

\title{
A comparison of the physiological profiles of elite Gaelic footballers, hurlers, and soccer players
}

\section{C McIntyre}

Br J Sports Med 2005;39:437-439. doi: 10.1136/bjsm.2004.013631

See end of article for authors' affiliations

.....................

Correspondence to: M C Mclntyre, Institute of Technology, Tralee, Tralee, Co. Kerry, Republic of Ireland; martin.mcintyre@ staff.ittralee.ie

Accepted 20 July 2004
Background: Gaelic football, soccer, and hurling are prominent field games in Ireland and involve participants undertaking a variety of playing tasks and skills which place various physiological demands on the participants. The aim of this study was to evaluate and compare the mid-season physiological profiles of elite players.

Methods: Physiological assessment was carried out on 29 inter-county Gaelic footballers, 30 inter-county hurlers, and 21 League of Ireland soccer players.

Results: Significant differences were reported for \% body fat $(p<0.05)$, aerobic capacity $(p<0.05)$, flexibility $(p<0.05)$, upper body strength $(p<0.05)$, upper body strength endurance $(p<0.05)$, abdominal endurance $(p<0.05)$, and speed endurance $(p<0.05)$, while there were no differences recorded for height, weight, or speed levels. A relatively heterogeneous body size is evident for all three sports. Soccer players had lower body fat levels, greater aerobic capacity, greater strength endurance, and greater flexibility compared to both Gaelic footballers and hurlers, possibly due to specific training and conditioning programmes or physical adaptation to match play The greater strength of both Gaelic footballers and hurlers and the superior speed endurance levels of Gaelic footballers also reflect the physical nature of the sports. Similar speed levels amongst all three sports reflect the importance of speed for performance.

Conclusions: The various physiological attributes for Gaelic football, soccer, and hurling reflect the physical requirements for success and participation in each of these field games.
G aelic football and hurling are the national sports of Ireland, while soccer is also a prominent field game. All three codes have many similarities in terms of playing tasks and playing skills. Gaelic football and hurling are similar in that each team comprises 14 outfield players positioned similarly and matches are $70 \mathrm{~min}$ in duration, while soccer teams are composed of 10 outfield players and matches are $90 \mathrm{~min}$ in duration. The main difference between Gaelic football and hurling is that Gaelic football is played with a ball similar to that used in soccer while hurling is played with a stick (a hurley) and a round ball similar in size to a handball (a sliothar). Each code places various demands on the aerobic system, and an intermittent emphasis on anaerobic metabolism and high intensity exercise, while strength, strength endurance, flexibility, and speed are all important components of fitness.

The physiology of soccer has been widely reviewed, ${ }^{12}$ and there have also been some investigations into both the physiological profiles ${ }^{3}$ and the physiological demands ${ }^{4}$ of Gaelic football. There is, however, a distinct lack of scientific knowledge about hurling. A direct comparison between each of the sports has not been conducted. Consequently, the purpose of this study was to examine the physiological profiles of elite players of these sports.

\section{METHODS}

Subjects were 29 inter-county Gaelic footballers, 30 intercounty hurlers, and 21 League of Ireland soccer players. Physiological assessment was conducted in the middle of each playing year for each of the field games.

Prior to physiological assessment each subject successfully completed a thorough health risk screening process ${ }^{5}$ without any clinically significant findings.

Height was measured to the nearest $0.1 \mathrm{~cm}$ using a stadiometer, while body mass was measured to the nearest
$0.1 \mathrm{~kg}$ using analogue scales (Seca, Hamburg, Germany). Percentage body fat was estimated by skinfold callipers using the four site method as outlined by Durnin and Wormersley. ${ }^{6}$ Maximal oxygen intake was estimated from a progressive $20 \mathrm{~m}$ shuttle run. ${ }^{7}$ Flexibility was measured via the sit and reach test and straight leg raise. The sit and reach test was conducted using a sit and reach box (Cranlea, Birmingham, UK), three trials were performed, and the maximum result recorded. Straight leg raise was measured with a Leighton Flexometer (Cranlea) using the method as outlined by Leighton. ${ }^{8}$ Upper body strength was measured via a 1 rep max (the maximum load that a person can lift only once) as outlined by Logan et $a l^{9}$ and both absolute and relative scores were recorded. Abdominal and upper body endurance was assessed via a 1 min sit up and press up test. Speed endurance was measured via six $30 \mathrm{~s}$ maximal shuttle runs over $5,10,15,20,25$, and $30 \mathrm{~m}$ interspersed with $30 \mathrm{~s}$ intervals for recovery. The total distance covered over the six runs was recorded for each subject. Speed was measured with a set of electronic timers (Pacesetter, Belfast, UK) over a distance of $0-15 \mathrm{~m}$. This test was performed from a standing start, three trials were performed, and the fastest time recorded.

The results were analysed using standard descriptive statistics, while analysis of variance (ANOVA) was used to examine between group variability.

\section{RESULTS}

There were no significant differences found for age, height, or weight between players of the three games (table 1). Soccer players were found to posses significantly lower levels of body fat $(\mathrm{p}<0.05)$ in comparison to both hurlers and footballers. Footballers were also found to have significantly lower body fat levels compared to hurlers $(p<0.05)$. Soccer players had significantly greater $\mathrm{Vo}_{2}$ max values than both 
Table 1 Physiological data for Gaelic football, hurling, and soccer players

\begin{tabular}{|c|c|c|c|}
\hline & Football $(n=30)$ & Hurling $(n=29)$ & ) Soccer $(n=21)$ \\
\hline Age & $24(6)$ & $24(5)$ & $23(6)$ \\
\hline Height & $179(6)$ & $177(6)$ & $177(5)$ \\
\hline Weight & $81(9)$ & $83(9)$ & $78(5)$ \\
\hline Est. \% body fat & $13.4(3) \dagger$ & $18.4(3)^{*}$ & $12.2(2)$ \\
\hline Est. $\mathrm{Vo}_{2}$ max. & 48.7 (7) & $47.4(7)$ & $57.6(5)^{*} \ddagger$ \\
\hline Sit and reach & $25(6)$ & $23(7)$ & $30(4)^{*}$ \\
\hline Straight leg raise & $65(8)$ & $88(9) \dagger$ & $88(8)^{-}$ \\
\hline 1 rep max & $73.7(12) \dagger$ & $63.2(15)$ & $68.1(13)^{*}$ \\
\hline Upper body end. & 46.8 (10) & $42.8(10)$ & $59.1(15)^{\star} \ddagger$ \\
\hline Abdominal end. & 47 (11) & $42(9)$ & $64(11)^{*} \ddagger$ \\
\hline Speed end. & $817(79) \dagger \neq$ & 667 (44) & $774(25)^{*}$ \\
\hline Speed & $2.53(0.1)$ & $2.49(0.1)$ & $2.48(0.1)$ \\
\hline
\end{tabular}

Values are means (SD). Est., estimated; end., endurance. *Significantly different for hurling $v$ soccer $(p<0.05)$; $†$ significantly different for hurling $v$ football $(p<0.05)$; †significantly different for football $v$ soccer $(p<0.05)$.

footballers and hurlers. Soccer players were found to possess greater flexibility levels for the sit and reach test than hurlers $(\mathrm{p}<0.05)$, while they also had greater hamstring flexibility in the straight leg raise than footballers, while hurlers also had greater hamstring flexibility than footballers $(p<0.05)$. Gaelic footballers had greater levels of strength during the 1 rep max than both hurlers and soccer players $(p<0.05)$, while soccer players had greater 1 rep max values than hurlers $(p<0.05)$. Soccer players had greater upper $(\mathrm{p}<0.05)$ and abdominal endurance $(\mathrm{p}<0.05)$ in comparison to both hurlers and footballers. Footballers were found to have greater speed endurance levels than both hurlers $(\mathrm{p}<0.05)$ and soccer players $(p<0.05)$, while soccer players $(p<0.05)$ had significantly greater speed endurance than hurlers. There was no difference in sprint times between any of the groups.

\section{DISCUSSION}

The age profiles of all teams were very similar. The age profiles of both the football and hurling teams were similar to mean (SD) values reported in the literature to range from 23.5 (4.9) to 26.8 (3.9) years for inter-county Gaelic footballers, ${ }^{10}{ }^{11}$ while the League of Ireland soccer team had a profile similar to that of an English third division club (25.8 (4.7) years) but slightly higher than a English Premier League club (22.5 (3.6) years). ${ }^{12}$

There were no differences reported for body mass between players of the three games. The values were similar to those reported for inter-county Gaelic footballers $(79.9$ (8.2) to 82.6 $(4.8) \mathrm{kg}),{ }^{3}{ }^{10}$ Australian Rules players $\left(81.1\right.$ (0.07) kg), ${ }^{13}$ Rugby Union forwards (83.1 (0.06) kg), ${ }^{14}$ and English Premier League soccer players $(77.7(7.6) \mathrm{kg}){ }^{12}$

Likewise, there was no difference in stature between any of the players. Gaelic footballers have previously been reported to range in stature from $1.79(0.07)$ to $1.83(0.05) \mathrm{m}^{11}{ }^{15}$ and professional soccer players from 1.75 to $1.83 \mathrm{~m} .{ }^{16}{ }^{17}$ These values are slightly lower than the reported values of 1.9 and $1.81(0.07) \mathrm{m}$ for Australian rules players and American footballers. ${ }^{13} 18$ The ranges in the current study reflect relatively heterogeneous body size. It is worth noting that inter-county Gaelic football teams have been found to be taller and heavier compared to club players. ${ }^{10}$

Soccer players were found to have significantly lower body fat levels than both Gaelic footballers and hurlers. The values reported here are similar to values previously reported in the literature. The percentage body fat of soccer players has previously been found to range between 9.8 and $10.7 \%$ for a number of studies reporting on full time soccer players both at club and international level, ${ }^{19-22}$ whilst differences between semi-professional and professional soccer players have also been reported by Brewer and Davis. ${ }^{23}$ In comparison, values reported for Gaelic football are slightly higher, ranging between 11 and 15\%. Gaelic football matches are $70 \mathrm{~min}$ in duration, therefore the energy demands on the player may be not as great as in soccer where match play is $90 \mathrm{~min}$ in duration. Furthermore, soccer players are full time professionals and the greater frequency of training and competition may be responsible for this difference, given that prolonged and long term levels of exercise in training and competition also reduce stored body fat. ${ }^{24}{ }^{25}$ Interestingly, footballers had lower body fat than hurlers, but it is unclear why this is.

The difference in the aerobic capacities of soccer players and Gaelic footballers and hurlers indicates a greater level of aerobic conditioning in soccer. This trend of soccer players possessing greater estimated $\mathrm{Vo}_{2}$ max values than both Gaelic footballers and hurlers is evident through the range of values reported in the literature. Values for elite soccer players have been reported to range between 55 and $70 \mathrm{ml} \mathrm{kg}^{-1} \min ^{-1}$, while estimated $\mathrm{Vo}_{2 \max }$ values for Gaelic football have ranged between 53.8 (3.8) and 58.6 (3.8) $\mathrm{ml} \mathrm{kg}^{-1} \mathrm{~min}^{-1}$. ${ }^{3}$ Therefore, it would seem there is a greater reliance on aerobic metabolism in soccer. However, the physiological strain of match play in soccer and Gaelic football has been estimated to be $70 \%^{26}$ and $72 \%^{4}$ of maximum oxygen uptake. As both sports exhibit similar physiological stress during competition, it would seem that better aerobic conditioning in soccer is responsible for this difference in aerobic capacity, particularly since in Gaelic football mean heart rate has been found to exceed 160 beats $\min ^{-1}$ for $43 \%$ of match play but only $26 \%$ of training time. This suggests that training in Gaelic football and hurling is inadequate to induce significant improvement in $\mathrm{Vo}_{2 \text { max }}$; however, more research is required.

Dunbar and Power ${ }^{12}$ investigated the flexibility of semiprofessional and professional soccer players and found no differences between the groups; the lack of flexibility was attributed to the fact that flexibility is not usually viewed as an important component of fitness for soccer. However, the values reported here exceed those reported by Dunbar and Power $^{12}$ and are more similar to values $(31 \mathrm{~cm})$ reported by Chin $e a^{27}$ for a professional soccer team in Hong Kong. The differences in sit and reach flexibility found in the present study indicate a greater level of flexibility in soccer players compared to Gaelic footballers and hurlers. It is unclear if this is due to a response to specific training and conditioning programmes or to physical adaptation to match play. However, Gaelic footballers had lower levels of hamstring flexibility during the straight leg raise in comparison to both soccer players and hurlers. Graham-Smith and Lees $^{28}$ investigated the risk of hamstring injury while taking a place kick in Rugby Union. They reported that an additional stretch of $10.9 \%$ was placed on the biceps femoris muscle in comparison to a maximal assisted stretch, thus placing the hamstrings at greater risk of injury. While the kicking action in Gaelic football is not identical to Rugby Union place kicking, it must also place the hamstrings at increased risk of injury. Overdevelopment of the psoas muscle can very often occur in kicking sports and places extra strain on the hamstring $\mathrm{s}^{29}$ and may help explain the lack of hamstring flexibility among Gaelic footballers. A comparison of lower back posture between the three groups would be beneficial as poor hamstring flexibility is also related to lower back posture. $^{30}$

Gaelic footballers had superior upper body strength as expected in a sport which requires upper body strength in resisting and instigating physical challenges, both in terms of ball retention and winning possession. This is evident in the upper body strength of the footballers during the 1 rep max. In soccer the physical challenges are not as robust and there is more an emphasis on skill levels when attempting to retain 


\section{What is already known on this topic}

Gaelic football, soccer, and hurling are prominent field games in Ireland and place various physiological demands on participants.

possession, and there is therefore less emphasis on upper body strength. Soccer players also differed significantly from hurlers. Agility and speed are crucial in hurling, while skill levels are also important. However, the upper body strength of the hurlers indicates a lack of specific strength training.

The greater upper and abdominal endurance of soccer players in comparison to Gaelic footballers and hurlers indicates the importance of strength endurance in soccer as players are required to repeatedly resist physical challenges during competition.

All three codes require intermittent levels of high intensity exercise and this is evident in the speed endurance scores. The difference in speed endurance levels between soccer and Gaelic footballers can be attributed to the difference in the distance covered while undertaking high intensity exercise. Time motion analysis of Gaelic football revealed that high intensity exercise accounted for $16 \%$ of the total distance covered $^{31}$ while in soccer it amounted to $8 \%{ }^{26}$ As a result Gaelic footballers are required to possess good speed endurance levels. The difference in speed endurance levels between hurlers and Gaelic footballers maybe due to the fact that in hurling the ball can often travel over 70 yards in one play, reducing the necessity to repeatedly sprint for long distances. Furthermore, players possess a high skill level, particularly at inter-county level where passes are often very accurate.

Speed is an important characteristic in all three codes in winning possession and evading opponents and is reflected in the identical speed scores in these sports.

\section{CONCLUSIONS}

The stature and body mass of players of the three sports indicate a relatively heterogeneous body size. Soccer players have lower levels of body fat than both Gaelic footballers and hurlers. This has been attributed to the greater playing time in soccer. The higher levels of body fat among hurlers indicate that leanness is not a prerequisite for participation in the sport. The difference in the aerobic capacities of soccer players and Gaelic footballers and hurlers indicates a greater level of aerobic conditioning in soccer and may be due to an adaptation to training and competition. Sit and reach flexibility compared well to other studies and the greater levels of flexibility of soccer players indicates it is a prerequisite for participation. The poor hamstring flexibility of Gaelic footballers may be linked to kicking and punting in the sport, however more research is required. The upper body strength of Gaelic footballers is somewhat higher than that of both soccer players and hurlers and is due to the physical nature of the game. The greater upper and abdominal endurance of soccer players indicates a greater level of abdominal conditioning. The greater speed endurance levels of Gaelic footballers maybe due to high intensity exercise during competition. Speed is an important physical attribute for participation in all sports. The trend and differences in the various physiological attributes for Gaelic football, soccer, and hurling can be attributed to a reliance on various physical attributes for participation in each of these particular field games.

Competing interests: none declared.
What this study adds

The various physiological attributes for Gaelic football, soccer, and hurling reflect the physical requirements for success and participation in each of these field games.

\section{REFERENCES}

1 Bangsbo J. The physiology of soccer - with special reference to intense intermittent exercise. Acta Physiol Scand 1994;150:615.

2 Reilly T. Football. In: Reilly T, Secher N, Snell P, et al. Physiology of sports. London: E \& FN Spon, 1990:465-87.

3 Reilly T, Doran D. Science and Gaelic football: a review. J Sports Sci 2001; 19:181-93.

4 Florida-James G, Reilly T. The physiological demands of Gaelic football. Br J Sports Med 1995;29:41-5.

5 Sports Medicine Australia. Guideline six. Supervision of fitness testing (cardio respiratory endurance). Belconnen, ACT: Sports Medicine Australia, 1994.

6 Durnin J, Wormersley J. Body fat assessed from total body density and its estimation from skinfold thickness: measurements on 481 men and women aged 16-72 years. Br J Nutr 1974;32:77-97.

7 Ramsbottom R, Brewer J, Williams C. A progressive shuttle run test to estimate maximal oxygen uptake. Br J Sports Med 1998;22:141-4.

8 Leighton R. Alternate leg flexion. Manual of instruction for Leighton flexometer. Lafayette Instrument Co.: London, 1987:12.

9 Logan $P$, Fornasiero D, Abernethy $P$, et al. Protocols for the assessment of isoinertial strength. In: Gore CJ, ed. Physiological tests for elite athletes. Australian Sports Commission. Champaign, IL: Human Kinetics, 2000:200-22.

10 Keane S, Reilly T, Borrie A. A comparison of fitness characteristics of elite and non elite Gaelic football players. J Sports Sci 1997;13:503.

11 Watson A. Physical and fitness characteristics of successful Gaelic footballers. Br J Sports Med 1995;29:229-31.

12 Dunbar G, Power K. Fitness profiles of English professional and semi professional soccer players using a battery of field tests. In: Reilly T, Bangsbo J, Hughes M, eds. Science and football III. London: E \& FN Spon, 1995:27-31.

13 Burke L, Read R, Gollan R. Australian Rules Football: an anthropometric study of participants. Br J Sports Med 1985;19:100-2.

14 Bell B. Body composition and maximal aerobic power of rugby union forwards. J Sports Med Phys Fitness 1980;20:447-51.

15 Kirgan B, Reilly T. A fitness evaluation of Gaelic football club players. In: Reilly T, Clarys J, Stibbe A, eds. Science and football II. London: E \& FN Spon, 1993:59-62.

16 Bangsbo J, Mizuno M. Morphological and metabolic alterations in soccer players with detraining and retraining and their relationship to performance. In: Reilly T, Lees A, Davids K, Murphy WJ, eds. Science and football. London: E \& FN Spon, 1998:114-24.

17 Willaims C, Coults R, Reid R. Observations on the aerobic power of university rugby players and professional soccer players. $\mathrm{Br} J$ Sports Med 1973;7:390-1.

18 Wilmore J, Haskell W. Body composition and endurance capacity of professional football players. J Appl Physiol 1972;33:564-7.

19 De Rose E. Determination of the ideal body weight and body composition of professional soccer players. In: Question of athletes nutrition: abstracts of the reports the International Symposium. Leningrad: Leningrad Institute of Physical Culture, 1975.

20 Raven P, Gettmen L, Pollock $M$, et al. A physiological evaluation of professional soccer players. Br J Sports Med 1978;10:209-16.

21 Rhodes E, Mosher R, McKenzie D, et al. Physiological profiles of the Canadian Olympic soccer team. Can J Appl Sports Sci 1986;11:31-6.

22 Withers R, Craig N, Bourdan P, et al. Relative body fat and anthropometric prediction of body density of male athletes. Eur J Appl Physiol 1987;56:191-200.

23 Brewer J, Davis J. A physiological comparison of English professional and semi-professional players. Communication to the Second World Congress on Science and Football, Eindhoven, The Netherlands, 1991.

24 Muthiah C, Sodhi $\mathrm{H}$. The effect of training on some morphological parameters of top ranking Indian basketball players. J Sports Med Phys Fitness 1980;20:405-12

25 Thompson S. The official encyclopaedia of baseball. New York: Barnes, 1959 .

26 Bangsbo J, ed. The physiology of match play. In: Fitness training in football a scientific approach. Bagsvaerd: HO+Storm, 1992:55-77.

27 Chin M, Lo Y, Li C, et al. Physiological profiles of Hong Kong elite soccer players. Br J Sports Med 1992;26:262-6.

28 Graham-Smith $\mathbf{P}$, Lees $A$. Risk assessment of hamstring injury in rugby union place kicking. In: Spinks W, Reilly T, Murphy A, eds. Science and football IV. London: Routledge, 2000:182-9.

29 Rasch P, Burke R. Kinesiology and applied anatomy. Philadelphia: Lea and Febiger, 1978

30 Hennessy L, Watson A. Flexibility and posture assessment in relation to hamstring injury. Br J Sports Med 1993;27:243-6.

31 Keane S, Reilly T, Hughes M. Analysis of work-rates in Gaelic football. Aust J Sci Med Sport 1993;25:100-2. 